WOODS HOLE OCEANOGRAPHIC INSTITUTION

Woods Hole, Massachusetts

In citing this manuscript in a bibliography, the reference should be followed by the phrase: UNPUBLISHED MANUSCRIPT

Reference No. 54-56

MARINE METEOROKOGY

On the Formation and Structure of Downdrafts in Cumulus Clouds

\title{
By
}

Joanne Starr Malkus

Technical Report No. 31

Submitted to the Office of Naval Research

Under Contract N6onr-27702 (NR-082-021)

August 1954

APPROVED FOR DISTRIBUTION 1014 trin

APPROVED FOR DISTRIBUTION $\frac{\text { Director }}{\text { RELEASE: }}$ 
Downdrafts, exhibiting speeds and mass transports comparable to those of the main updrafts, are a common feature of the cumulus clouds studied by the Woods Hole Oceanographic Institution's PBY aircraft in the trade-wind region. These downdrafts are observed to be most pronounced at the extreme downshear edge of the visible cloud and are generally stronger the greater the age of the cloud tower, although they are normally present at the edge of even rapidly growing turrets.

The cloud data obtained by the PBI on the 1952 Caribbean trip (reported on by Malkus, 1954, in a paper hereinafter referred to as I) suggested that these downdrafts mixed primarily with the air of the adjacent updraft, rather than with the drier air of the clear environment. This is plausible in view of the hypothesis voiced by the writer (1949, 1952) that air is moving through an updraft in the direction pointed by the shear vector; that is, an updraft entrains air mainly on the upshear side and sheds air mainly from its downshear side. Regarding a cumulus draft in terms of the bubble-like elements which compose it (see Malkus and Scorer, 1955), the same conclusion is reached when we consider that in a shearing wind field, the wake region is found downshear of the ascending buoyant elements.

The data available from the March-April 1953 trade-wind cloud flights now make it possible to set up a tentative physical theory concerning the origin and structure of these downdrafts at the edge of the clouds. It is suggested and made plausible by the calculations to follow that the downdraft originates at the top of the cloud from air which has recently been part of the updraft. Air shed from the updraft at cloud top nay, because of slight dilution by the surroundings and evaporation of roughly $10 \%$ of its liquid water content, acquire sufficient negative broyancy to begin a rapid 
downward acceleration, once given a small initial downward velocity of the order of magnitude observed in the turbulent fluctuations at cloud boundaries. In fact, the low stability of the common trade cumulus environment would permit extreme downward velocities to develop were there not constant braking due to entrainment of air with upward momentum, as will be illustrated.

The set of cloud traverses discussed here (through a single cloud observed on April 7, 1953) were made in a manner identical to those described in $I$, except that the vertical draft records are considerably more accurate, so that one-fifth second averages of $w$ (draft values over about $10-12 \mathrm{~m}$ horizontal distance) may be relied on to better than 15\% (see Bunker, 1954). This improvement is due primarily to the fact that in integrating the accelerometer records, accurate corrections to the aircraft's sinking speed caused by airspeed and attitude variations are now incorporated, rather than assumed to be negligible as in $I$.

The calculations from this set of traverses are based upon the steadystate model of an entraining cumulus draft described in I. In that paper, the relations between parameters prescribed by the steady-state model were shown to hold-fairly adequately even when the cloud visibly departed from steady conditions (see Cloud II, Ioc. cit.) and for two separate clouds in widely differing phases of their life cycles. It is therefore contended that the development and decay of a single cloud may be approximated by a series of quasi-steady states.

Under steady conditions, the equation for conservation of vertical momentum (equation 8 in I) states that 


$$
\frac{1}{w_{d o}-w_{E}} \frac{d w_{d}}{d z}=-\frac{1}{M} \frac{d M_{i}}{d z}+\frac{\bar{\alpha}}{w_{d o}\left(w_{d o}-w_{E}\right)}
$$

where the $\mathrm{z}$-axis points upward and a small height interval between $\mathrm{z}$ and $z+d z$ is considered. Verticel velocities are denoted by $w$, where $w_{d}$ is the average velocity across the draft at $\mathrm{z}+\mathrm{dz}$; $\mathrm{w}_{\mathrm{do}}$ is the corresponding value at $z$, and $w_{E}$ is the average vertical motion of the nearby enviroment (actually of the entrained air). $M$ is the average mass flux across the draft, so that $1 / \mathrm{M} \mathrm{dM_{j }} / \mathrm{dz}$ is the gross entrainment between $\mathrm{z}$ and $\mathrm{z}+\mathrm{dz}$ calculated by Stommel's method, $M_{i}$ being the total mass flux entrained in the height interval. The buoyancy acceleration, $\alpha$, is defined as $g\left(T_{\nabla}-T_{v}^{\prime}\right) / T_{v}^{\prime}$ where $g$ is the acceleration of gravity; $T_{V}$ is the mean virtual temperature of the draft air; and $T_{\nabla}^{8}$ is the virtual temperature of the environment. The value $\bar{\alpha}$ denotes an aversging of the mean draft buoyancy between $z$ and $z+d z$. Equation (1) is exact (under the assumed conditions) except for the omission of an additional drag term due to form drag and weight of suspended hydrometeors, which omission was justified by the previous observations. A further approximation to equation (I) was introduced in I since it was felt that the 1952 draft measurements were not sufficiently accurate to estimate $W_{E}$. This approximation has now been dropped and the observations are used directly in equation (1) as follows: the draft boundaries are defined at the point where the vertical velocity becomes zero. The major up- and downdrafts so defined are readily traceable from one level to the next on the reconstructed cloud cross section (draft profile presented in Figure 1). The average values across draft boundaries of w, $\mathrm{T}$ (actual temperature), $\mathrm{T}_{\mathrm{v}}, \mathrm{q}$ (mixing ratio), 
etc. are then made graphically at each level traversed from plotted diagrams similar to Figures 4-9 of I. The main updraft in the cloud (marked on Figure 1) is first considered. The gross entrainment between each two successive observed levels of this draft is calculated and the results are presented in Table 1 and Figure 2.

\section{Table I}

Gross entrainment in the updraft

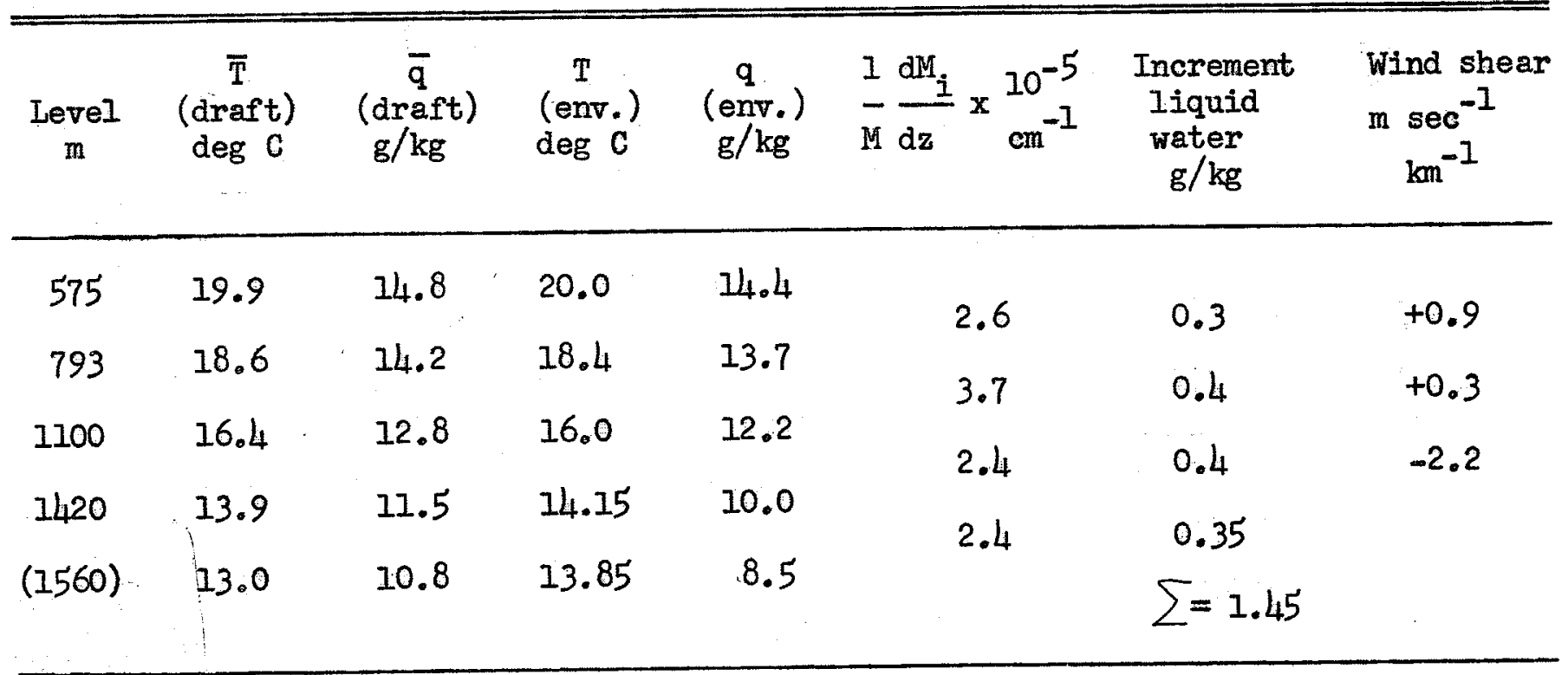

Next the draft profile in the updraft is calculated using equation ( 1 ) and the horizontal traverses, similarly to the procedure in $I$. The first step is made by taking for $w_{d o}$ in the equation the observed average updraft at $575 \mathrm{~m}$, calculating $d w_{d} / d z$ from there up to $793 \mathrm{~m}$, etc. The results are presented in Table 2, in which the last two columns give side-by-side the calculated at each height compared to the value arrived at by a graphical averaging across the draft of the observed values shown in Figure 1. 
Table 2

Draft calculation for the updraft

\begin{tabular}{|c|c|c|c|c|c|c|c|c|}
\hline $\begin{array}{c}\text { Level } \\
\text { m }\end{array}$ & ${ }_{\operatorname{deg}}^{T} K$ & $\stackrel{T_{v}^{\prime}}{\operatorname{deg} K}$ & $\begin{array}{c}\bar{\alpha} \\
\mathrm{cm} / \mathrm{sec}^{2}\end{array}$ & $\begin{array}{c}\mathrm{w}_{\mathrm{do}} \\
\mathrm{cm} / \mathrm{sec}\end{array}$ & $\begin{array}{c}w_{E} \\
\mathrm{~cm} / \mathrm{sec}\end{array}$ & $\begin{array}{c}\Delta \mathrm{w} \\
\mathrm{cm} / \mathrm{sec}\end{array}$ & $\begin{array}{c}\mathrm{w}_{\mathrm{d}}(\operatorname{col} \mathrm{c}) \\
\mathrm{cm} / \mathrm{sec}\end{array}$ & $\begin{array}{c}w_{d} \text { (obs.) } \\
\mathrm{cm} / \mathrm{sec}\end{array}$ \\
\hline 575 & 22.50 & 22.50 & \multirow{2}{*}{$\begin{array}{l}0.50 \\
1.35\end{array}$} & 150 & \multirow{2}{*}{$\begin{array}{l}-20 \\
-60\end{array}$} & \multirow{2}{*}{-.24} & & \\
\hline 793 & 21.10 & 20.80 & & 126 & & & 126 & 110 \\
\hline 1100 & 18.60 & 18.10 & \multirow{3}{*}{$\begin{array}{r}0.85 \\
-0.78\end{array}$} & 240 & \multirow{3}{*}{$\begin{array}{c}-50 \\
0\end{array}$} & \multirow{3}{*}{$\begin{array}{l}-110 \\
-128\end{array}$} & 240 & 220 \\
\hline 1420 & 15.90 & 15.90 & & 130 & & & 130 & 140 \\
\hline$(1560)$ & 14.85 & 15.30 & & & & & 2 & $\sim 0$ \\
\hline
\end{tabular}

The highest level at which measurements were made within the cloud was at $1420 \mathrm{~m}$ or $4500 \mathrm{ft}$. The highest traverse made by the airplane was at $5400 \mathrm{ft}$, which however passed above the cloud top by about $300 \mathrm{ft}$. In order to discuss the formation of the downdraft, the updraft has been constructed upward from the $I_{4} 20 \mathrm{~m}$ traverse to $1560 \mathrm{~m}$ ( $5000 \mathrm{ft}$ ). This was done by assuming that rate of entrainment (comparable to values measured in nearby levels) which will give cloud properties at $1560 \mathrm{~m}$ such that the updraft is reduced to approximately zero velocity there. This could be used as a criterion since the tower top was observed to be rising no longer. These calculated values are the ones presented for the $1560 \mathrm{~m}$ level in Tables $I$ and 2. A hypothesis concerning the manner in which the downdraft formed near the downshear edge of the visible cloud at this height will now be tested. It will be determined whether air with these calculated properties, after a slight dilution with outside envirorment air of known properties, could show up at the successively lower levels with the observed properties of the downdraft actually studied and 
marked in Figure 1. If the cloud is not precipitating (this cloud never did) and if the major fraction of its liquid water lies in drops of low fall velocity $(\leq I \mathrm{~mm})$, the liquid water content at the cloud top will be approximately the sum of the increments in column seven of Table 1, namely 1.45 $\mathrm{g} / \mathrm{kg}$. If, at the upper cloud edge, after the updraft has gone to nearly zero, we make a mixture consisting of $84 \%$ updraft air and $16 \%$ outside clear air, and if we evaporate $0.15 \mathrm{~g} / \mathrm{kg}$ liquid water, we obtain air of $\mathrm{T}=12.8 \mathrm{C}$ and $q=10.6 \mathrm{~g} / \mathrm{kg}$ water vapor, which is close to saturation and possessing a strong negative buoyancy. If such air is given a slight downward push, it should accelexate downward very rapidly due to the instability of the environment. In fact, the braking action of entrainment must come into play or the downdraft would possess magnitudes far greater than observed.

We are, however, considering a quasi-steady situation. The question to ask is whether air starting at $1560 \mathrm{~m}$ with the above properties can sink to $1420 \mathrm{~m}$, and by reasonable amounts of mixing with the surroundings, appear at the latter level with the observed properties of the downdraft. We shall assume here that the downdraft air is mixing only with air from the adjacent updraft and but negligibly thenceforth with the clear air. This is quite a different hypothesis from that used in the work of the Thunderstorm Project (see Byers and Braham, 1949, Fig. 33 and p. 38) and requires some explanation. It was suggested by the downdraft calculations for the 1952 clouds (see Table 6 of I) that the downdraft obtained most of its air from the updraft. If in the present calculation, significant entrainment from the clear is assumed, the downdraft calculation becomes quite absurd and no possible admixture is found which gives the downdraft the observed properties from one level to the next. 
Figure 3 shows the entraimnent calculation for the downdraft marked on Figure 1. Point $A$ is obtained for the downdraft at $1560 \mathrm{~m}$, as indicated above, by first mixing $84 \%$ updraft air (curve U) with $16 \%$ clear air (curve CL) and then evaporating $0.15 \mathrm{~g} / \mathrm{kg}$ liquid water. To arrive at point $B$, the observed downdraft properties at $1420 \mathrm{~m}$, air with properties $A(T=12.8 \mathrm{C} ; q=10.6 \mathrm{~g} / \mathrm{kg}$; liquid water $=1.45-0.15=1.3 \mathrm{~g} / \mathrm{kg}$ ) must entrain from the updraft at a rate $2.0 \times 10^{-5} \mathrm{~cm}^{-1}$ and evaporate $0.15 \mathrm{~g} / \mathrm{kg}$ additional liquid water. From Il 20 to $1100 \mathrm{~m}$ (the lowest level to which this downdraft penetrated vigorously on the cross section), in order to arrive with the observed properties $C$, the entrainment rate from the updraft must have stayed nearly the same and an additional $0.47 \mathrm{~g} / \mathrm{kg}$ liquid water must have been evaporated. If the downdraft were entraining any significant amounts of air from the clear surroundings, the entrainment rate calculated from our data becomes absurdly large. This situation is physically visualized as follows: the more that the air entrained by the downdraft contains air from the clear, the drier is the entrained air. As the properties of the entrained air approach those of the air observed in the downdraft, the higher is the calculated entrainnent rate, up to that point where the average properties of the entrained air become drier than the draft, when the calculated proportion entrained decreases again. However, Figure 3 shows that reasonable entraiment rates of drier air than that in the downdraft would give draft air far drier than actually observed. Thus it must be concluded that at this stage of this cloud, the observed downdraft is composed almost entirely of air originally in the updraft. This gives rise to a downdraft in which the temperature lapse rate is steeper than moist adiabatic, rather than more stable than moist adiabatic as in Figure 33 of 
the Thunderstorm Report (10c. cit.) in which the downdraft is entraining clear air.

The entrainment calculation for the downdraft is presented in Table 3.

Table 3

Gross entrainment in the downdraft

\begin{tabular}{|c|c|c|c|c|c|c|c|c|c|}
\hline $\begin{array}{l}\text { Level } \\
\qquad \mathrm{m}\end{array}$ & $\begin{array}{c}\bar{T} \\
\text { (down- } \\
\text { draft) } \\
\operatorname{deg} \mathrm{C}\end{array}$ & $\begin{array}{c}\bar{q} \\
\text { (down- } \\
\text { draft) } \\
\text { g/kg }\end{array}$ & $\begin{array}{c}\mathrm{T} \\
\text { (updraft) } \\
\operatorname{deg} \mathrm{C}\end{array}$ & $\begin{array}{c}\mathrm{q} \\
\text { (updraft) } \\
g / k g\end{array}$ & $\begin{array}{c}\text { T } \\
\text { (clear) } \\
\operatorname{deg} C\end{array}$ & $\begin{array}{l}\text { (clear) } \\
\mathrm{g} / \mathrm{kg}\end{array}$ & $\frac{1}{M} \frac{d M_{i}}{d z}$ & $=\mathrm{x}^{10^{5}} \mathrm{~cm}^{-1}$ & $\begin{array}{l}\text { Evap. } \\
\mathrm{g} / \mathrm{kg}\end{array}$ \\
\hline$(1560)$ & 12.8 & 10.6 & 13.0 & 10.8 & 13.65 & 8.5 & & 2.0 & 0.15 \\
\hline 1420 & 13.75 & 10.9 & 13.8 & 11.5 & 14.4 & 9.5 & & 1.9 & 0.47 \\
\hline 1100 & 15.7 & 11.8 & 16.2 & 12.1 & 16.0 & 11.3 & & 4.7 & 0.48 \\
\hline 793 & 18.2 & 13.5 & 18.6 & 14.2 & 18.5 & 12.0 & & & \\
\hline
\end{tabular}

The resulting entrainment rates are now comparable to those of the updraft, similar to the 1952 elouds. The total evaporation of liquid water by the time the $1100 \mathrm{~m}$ level is reached is the sum of the figures in the last column of Table 3 plus the original $0.15 \mathrm{~g} / \mathrm{kg}$ hypothesized evaporated at $1560 \mathrm{~m}$, namely a total of $0.17 \mathrm{~g} / \mathrm{kg}$. By $793 \mathrm{~m}$ it is seen that this downdraft must have essentially disappeared. The entrainment rate becomes large, and 1.25 out of the maximum possible $1.45 \mathrm{~g} / \mathrm{kg}$ liquid water content has been evaporated. The disappearance of the downdraft by $793 \mathrm{~m}$ is even better illustrated in Table 4 , which gives the draft calculation for the downdraft. Table 4 may be regarded as a check upon the previous assumptions and calculations, since it is possible to compare the velocity profile arrived at using the temperatures, mixing ratios, and entrainment rates obtained and the actually measured velocity 
profile of the downdraft. This comparison is made in the last two columns of the table.

Table 4

Draft calculation for the downdraft

\begin{tabular}{|c|c|c|c|c|c|c|c|c|}
\hline $\begin{array}{c}\text { Level } \\
\text { m }\end{array}$ & $I_{\nabla} \operatorname{deg}_{K}$ & $\mathrm{~T}_{\mathrm{V}}^{\prime} \mathrm{K}$ & $\bar{\alpha}_{\mathrm{cm} / \mathrm{sec}^{2}}$ & $\begin{array}{l}\mathrm{w}_{\mathrm{do}} \\
\mathrm{cm} / \mathrm{sec}\end{array}$ & $\begin{array}{c}\mathrm{w}_{\mathrm{E}} \\
\mathrm{cm} / \mathrm{sec}\end{array}$ & $\begin{array}{l}\Delta \mathrm{w} \\
\mathrm{cm} / \mathrm{sec}\end{array}$ & $\begin{array}{c}w_{d}(\text { calc. }) \\
\mathrm{cm} / \mathrm{sec}\end{array}$ & $\begin{array}{c}\mathrm{w}_{\mathrm{d}}(\mathrm{obs} .) \\
\mathrm{cm} / \mathrm{sec}\end{array}$ \\
\hline$(1560)$ & 14.6 & 14.95 & & -60 & +700 & & & \\
\hline 1420 & 15.65 & 16.0 & $\begin{array}{l}-1.20 \\
-1.65\end{array}$ & -290 & +100 & $\begin{array}{r}-230 \\
+50\end{array}$ & -290 & -250 \\
\hline 1700 & 17.70 & 18.3 & -1.96 & -240 & +100 & +230 & -240 & -230 \\
\hline 793 & 20.55 & 21.1 & & & & & -10 & -30 \\
\hline
\end{tabular}

The virtual temperature of the downdraft air at $1560 \mathrm{~m}$ was taken as that of air at $12.8 \mathrm{C}, 10.6 \mathrm{~g} / \mathrm{kg}$ water, vapor. The virtual temperature of its environment was found from the average figures for updraft and enviroment given in Table 3. The initial downward velocity, $w_{\text {do }}$, at $1560 \mathrm{~m}$ was taken simply from the magnitude of turbulent fluctuations in w near the cloud boundaries at that height. The remaining figures were obtained from the cloud traverses in the same manner as in $I$. . .

The disappearance of the downdraft at $793 \mathrm{~m}$ is also plausible in view of the fact that below this level the wind shear is reversed in sign, being positive, so that a downdraft should appear thenceforth on the opposite, i.e. downwind, side of the cloud. The observational evidence on this point is in the present case inconclusive. It is pertinent to note, however, that the normal situation in the trade-wind cloud layer is a reversal of wind shear, 
from positive up to about $1100 \mathrm{~m}$ to negative above that. If the present hypothesis concerning the origin and structure of cumulus downdrafts is correct, this reversal of shear should make it difficult for the main downdraft, which starts near the top of the cloud on the upwind side, to penetrate downward to cloud base or lower before exhausting its liquid water. Fxceptions might be found in the cases of very large cumulonimbus clouds, such as those studied by Malkus and Ronne (1954) which reached great heights and possessed undilute cores with presumably high liquid water contents.

It may be seen by reference to Figure 3 that although the observations in this particular case preclude significant entrainment of clear air by the downdraft, such a situation (as described by Byers and Braham, 1949, p. 38) is by no means physically proscribed. If the downdraft entrained outside air, it could maintain the same or even greater negative buoyancy merely by evaporating liquid water at a faster rate. It would, of necessity, have to do this if mixing with clear air, because so long as any liquid water remains it will evaporate until the draft air is nearly saturated.

In fact, this situation may be quite pertinent to a still later stage in the life cycle of the cloud tower. As the tower ages, its updraft weakens and the air in the updraft becomes closer in its properties to the air of the clear enviromment with which it is mixing. The downdraft, thus, receiving the majority of its air from the updraft, will be entraining air of properties somewhat closer to curve $C L$ in Figure 3 than is curve $J$, i.e., drier and colder. In order to remain saturated, the downdraft then must evaporate its liquid water faster. If such water is available in large enough quantities, it may be shown by a calculation similar to those foregoing that the downdraft then will exhibit negative buoyancy equal to or 
greater than that calculated in Table 4 . With the weakened braking effect of the updraft, $W_{E}$ will be smaller, and it may be shown for the environment studied here and reasonable values of the updraft parameters, that the downdraft may reach $1420 \mathrm{~m}$ and $1100 \mathrm{~m}$ increased in intensity by $1 \mathrm{mps}$ or more. As the updraft dies completely and the cloud top begins to evaporate, the downdraft, too, cannot last much longer, as its source of cooling, namely evaporation of liquid water, will soon give out.

Conversely, it may be shown that in an earlier stage of the updraft, although the downdraft is enabled to be more economical with its liquid water, the larger braking effect of the adjacent updraft will, under reasonable assumptions, restrain the downdraft magnitudes below the values given in Table 4.

It is thus possible to describe the structure of the cumulus downdraft in one stage of its development quantitatively in terms of a steady-state model. It is plausible in view of these calculations to believe that most of the air composing the downdraft was originally entrained from the updraft and that the primary source of the downward acceleration is due to the evaporation of liquid water. It does not appear to be necessary to call upon the weight of nor the drag exerted by the liquid drops to assure the needed downward force. It further seems possible, by regarding a series of quasi-steady states, to project the downdraft both backward and forward in its life cycle and to see how its time-dependent behavior is related to that of the updraft upshear of it. It seems evident from this work that the behavior of the downdraft is intimately dependent upon that of the updraft which, in this paper, was measured or extrapolated from measurements. The time-dependent behavior of the updraft itself has not been analyzed herein, although it may be suggested in conclusion that a similar approach might be applied to that more fundamental problem. 


\section{Acknowledgments}

The draft observations, which form the basis of this paper, were reduced from the original records by the skill and diligence of Mrs. Mary C. Thayer, with the advice and assistance of Miss Martha A. Walsh who devised many of the reduction procedures.

\section{$\underline{\text { References }}$}

Bunker, A. F., 1954: WHOI airplane turbulence and flux measurements, O'Neill, Nebraska, August 21-28, 1953. Woods Hole Oceanogr. Inst. Ref. No. 54-25. Unpublished manuscript.

Byers, H. R. and R. R. Braham, 1949: The Thunderstorm. Report of the Thunderstorm Project. Washington. U. S. Gov't Printing Office, $282 \mathrm{pp}$.

Malkus, J. S., 1949: Effects of wind shear on some aspects of convection. Trans. Amer. Geophys. Un., 30, 19-25.

Malkus, J. S., 1952: Recent advances in the study of convective clouds. Tellus, 4, 71-87.

Malkus, J. So, 1954: Some results of a trade-cumulus cloud investigation. J. Meteor., 17, 220-237.

Malkus, J. S. and C. Ronne, 1954: On the structure of some cumulonimbus clouds which penetrated the high tropical troposphere. Woods Hole Oceanogr. Inst. Ref. No. 54-18. Unpublished manuscript. To be published.

Malkus, J. S. and R. S. Scorer, 1955: The erosion of cumulus towers. J. Meteor. In press. 


\section{TITLES FOR ILLUSTRATIONS}

Fig. 1. Reconstructed cross section of the cloud studied by the PBY on April 7, 1953, showing the measured vertical draft profile. The cloud formed over open ocean about 100 miles northeast of San Juan, Puerto Rico. The airplane passes were made, from the top downward, in alternate directions approximately up- and downwind. The wind component along the section flown is given at the right. The major up- and downdraft used in the calculations are denoted by the vertical lines drawn at each level. Peak draft velocities in $\mathrm{m} \mathrm{sec}^{-1}$ are indicated. Averages across the drafts are presented in the text.

Fig. 2. Entrainment calculation for the major updraft in the cloud shown in Fig. 1, using Stommel's method. The vertical coordinate is temperature in degrees Centigrade, while the horizontal coordinate is mixing ratio in $\mathrm{g} / \mathrm{kg}$. The curve $\mathrm{E}$ gives the properties of the nearby environment of the draft observed at each of the levels indicated (meters above sea level), while eurve $U$ gives the corresponding properties of the draft observed at all levels except $1560 \mathrm{~m}$, which value was obtained by a calculation described in the text. The vertical lines downward from each point represent dry adiabatic cooling. The line joining the end of the vertical line to the corresponding environment point is the mixing line, and the final slanting line to the draft point represents condensation of liquid water. The ratio of entrained air (mass flux) to mass flux already in the draft between successive levels is thus the ratio of the right-hand to the lefthand portion of the mixing line intercepted by the condensation line. 
Fig. 3. Entrainment calculation for the major downdraft in the cloud shown in Fig. 1. Exactly the same procedure was followed as illustrated in Fig. 2, except that the processes are in reverse, as described in the text. Curve CL gives the observed points for the clear air environment of the downdraft; curve 0 gives the observed or calculated nearby updraft properties; and curve $\mathbb{D}$ gives the observed downdraft properties, except for point $A$, which was calculated. The updraft curve, $U$, is not everywhere quite the same as the $U$ curve in Fig. 2, since here that portion of the updraft nearest the downdraft was considered, while Fig. 2 gives the average properties across the entire updraft. 


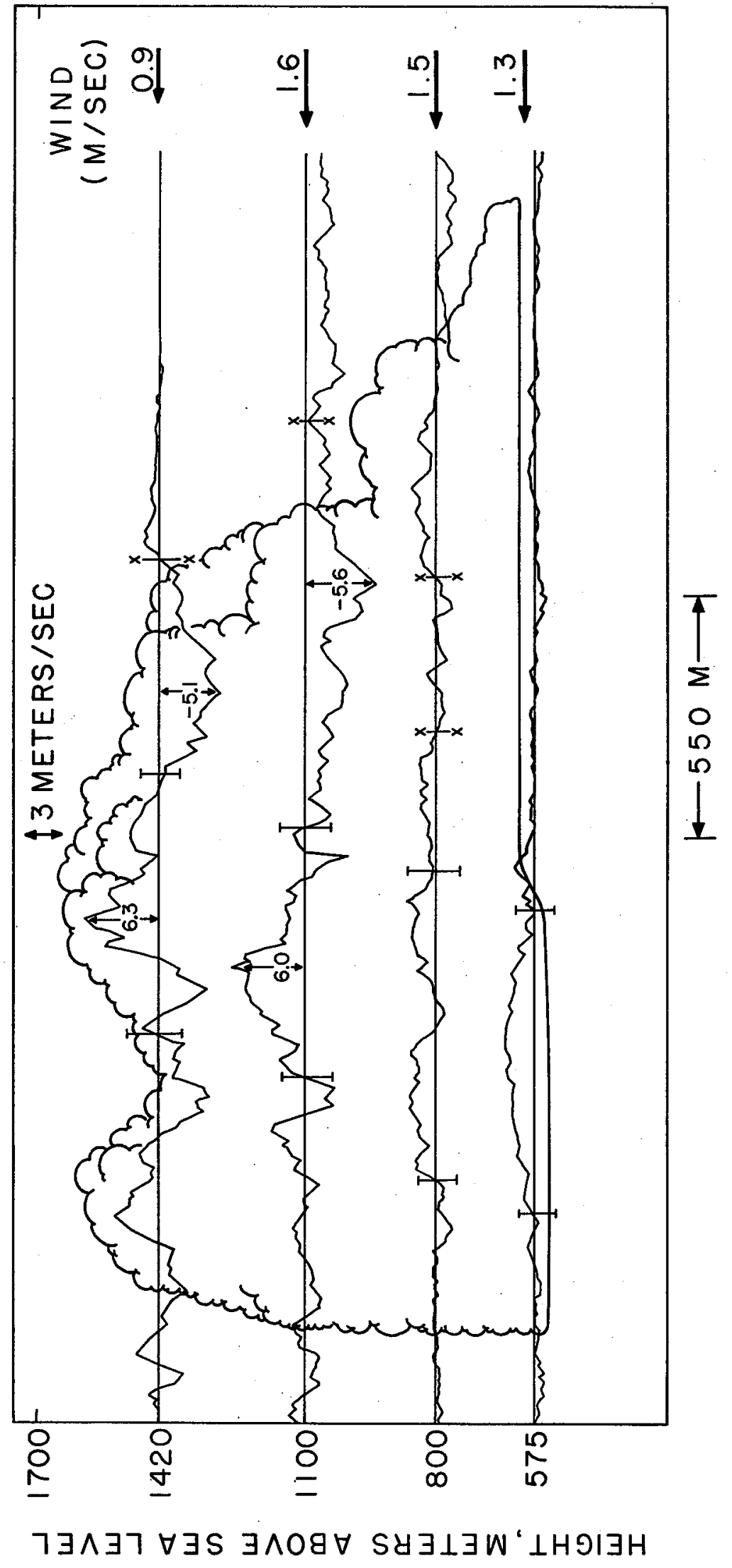

FIG. I 


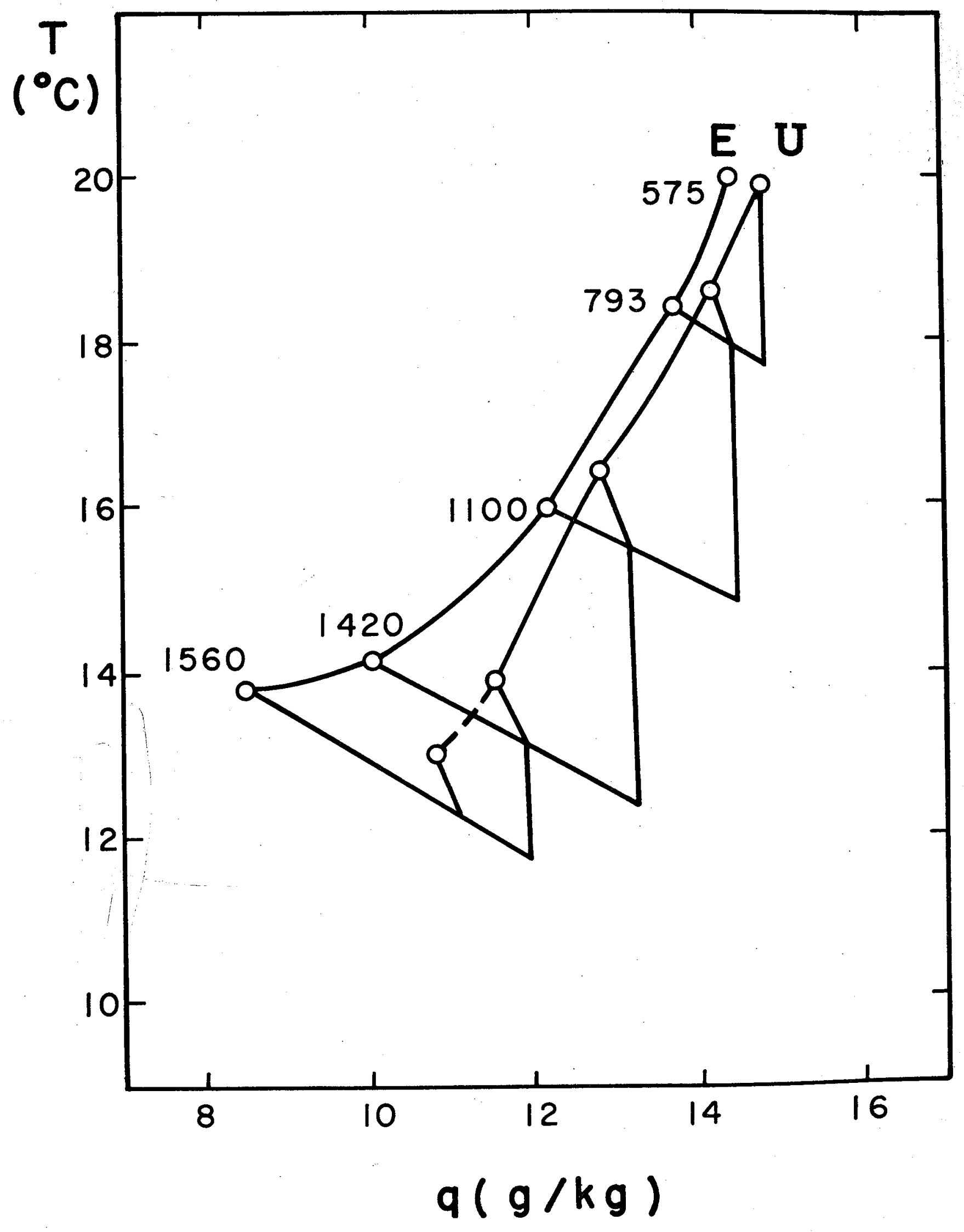

FIG. 2 


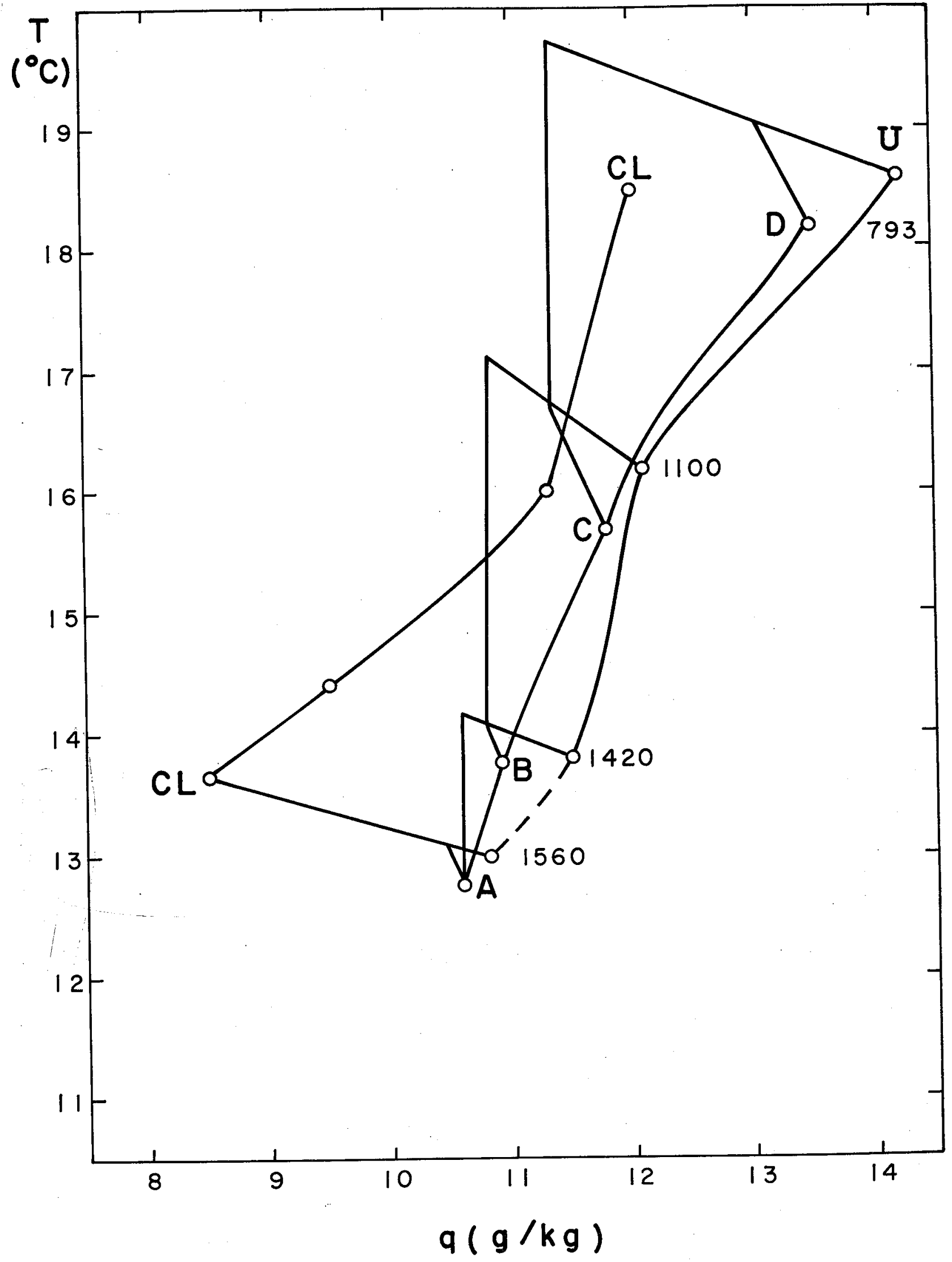

F́G.3 
Geophysics Branch, Code 416

Office of Naval Research

Washington 25, D。C.

Director, Naval Research Laboratory

Washington $25, \mathrm{~B} . \mathrm{C}$.

Attn: Technical Information Officer

Officer-in-Charge, Office of Naval Research

Iondon Branch Office, Havy No. 100

Fleet Post Office

New York, New York

Office of Naval Research Branch Office

346 Broadway

New York 13, New York

Office of Naval Research Branch Office

150 Causeway Street

Boston, Massachusetts

Office of Naval Research Branch Office Tentb Floor, The John Crerar Library Building 86 East Randolph Street Chicago, Illinois

Office of Naval Research Branch Office 1030 East Green Street Pasadena 1, California

Office of Haval Research Branch Office 1000 Geary Street

San Francisco, California

Office of Technical Services

Department of Commerce

Washington 25, D. C。 
Armed Services Technical Information Center Document Service Center

Knott Building

Dayton 2, Ohio

Assistant Secretary of Defense for Research and Development

Pentagon Building

Washington 25, D。C.

Attn: Committee on Geophysics and

Geography

Department of Aerology

U. S. Naval Post Graduate School

Lonterey, California

Aerology Branch

Bureau of Aeronautics (Ma-5)

Navy Department

Washington 25, Do C.

Mechanics Bivision, Naval Research Laboratory Anacostia Station

Washington $20, D$. C.

Attn: Jo E. Dinger, Code 7110

Radio Division I, Code 7150

Naval Research Laboratory

Anacostia Station

Washington $20, D_{0} C$.

Meteorology Section. Navy Electronics

Laboratory

San Diego 52, California

Attn: $L_{0} J_{0}$ Anderson

Library, Naval Ordnance Laboratory

White Dak

Silver Spring 19, Maryland 
Project Arowa, U. S. Naval Air Station Building Ros 48

Norfolk, Virginia

The Chief, Armed Forces Special Weapons Projecto

P. 0. Box 2610

Washington, D。 Co

Office of the Chief Signal Officer

Engineering and Technical Service

Washington $25, \mathrm{D}$. C.

Meteorological Branch

Evans Signal Laboratory

Belmar, New Jersey

Headquarters Quartermaster Research and Development Command

Quartermaster Research and Development Center U. S。 Army

Natick, Massachusetts Attr: Environmental Protection Division

Office of the Chief, Chemical Corps

Research and Engineering Division

Research Branch

Army Chemical Center, Maryland

Commanding Officer

Air Force Cambridge Research Center 230 Albany Street

Cambridge, Massachusetts Attn: ERHS- 1

Headquarters, Air Weather Service Andrews Air Force Base

Washington $20, D$ 。 C 。 
Commanding General, Air Materiel Command Wright Field Dayton, Ohio Attn: MCREEF

Commanding General, Air Force Cambridge Research Genter 230 Albany Street Cambridge, Massachusetts Attn: CRHSL

Commanding General, Air Research and Development Command

P. O. Box 1395

Baltimore 3, Maryland

Department of Meteorology

Massachusetts Institute of Technology Cambridge, Massachusetts Attn: H. G. Houghton

Department of Meteorology

University of Chicago

Chicago 37, IIlinois Attn: H. R. Byers

Institute for Advanced Study

Princeton, New Jersey Attn: Jo von Neumann

Scripps Institution of Oceanography La Jolla, California Attn: $R$ o Revelle

General Flectric Research Laboratory Schenectady, New York 
St. Iouis University

3621 0live Street

St. Louis 8, Missouri

Attn: Jo Bo Macelwane, S. J.

Department of Meteorology, University of

California at Los Angeles

Los Angeles, California

Attn: $\mathbf{M}_{0}$ Neiburger

Department of Engineering, University of California at Ios Angeles

Ios Angeles, California Attn: Lo Mo Ko Boelter

Department of Meteorology

Florida State University

Tallahassee, Florida Attn: Wo A. Baum

Woods Hole Oceanographic Institution

Woods Hole, Massachusetts Attn: C. Iselin

The Johns Hopkins University

Department of Civil Engineering

Baltimore, Maryland

Attn: $R_{0}$ Long

New Mexico Institute of Mining and Technology Research and Development Division

Socorro, New Mexico

Attn: $E_{\text {。 }}$ Workman

University of Chicago

Department of Meteorology

Chicago 37, Illinois

Attr: Ho Riehl 
Woods Hole Oceanographic Institution Woods Hole, Massachusetts Attn: A. Woodeock

General Blectric Research Laboratory Schenectady, New York Attn: V. Schaefer

Geophysical Institute University of Alaska College, Alaska Attn: C. T. Blvey

Blue Hill Meteorological Observatory Harvard University Milton 86, Massachusetts Attn: C. Brooks

Laboratory of Climatology Johns Hopkins University Seabrook, New Jersey

Department of Meteorology and Oceanography New York University New York 53, New York Attn: B. Haurwitz

Texas $A$ and $M$, Department of Oceanography College Station, Texas

$$
\text { Attn: Jo Freeman, Jr。 }
$$

Massachusetts Institute of Technology Department of Meteorology 77 Massalehusetts Arenue Cambridge 39, Massachusetts Attn: T. F. Nalone 
Rutgers University, College of Agriculture Department of Meteorology New Brunswick, New Jersey

National Advisory Committee of Aeronautics 1500 New Hampshire Avenue, N. W. Washington 25, D. C.

U. S. Weather Bureau

24th and If Streets, NoW.

Washington $25, \mathrm{D}$. C. Attn: Scientific Services Division

Air Coordinating Committee

Subcommittee on Aviation Meteorology

Room 2D889-A, The Pentagon

Washington, D. C.

American Meteorological Society

3 Joy Street

Boston 8, Massachusetts

Attn: The Executive Secretary

Research Professor of Aerological Engineering College of Engineering

Department of Electrical Engineering

University of Florida

Gainesville, Florida

The Hydrographer

U. S. Navy Hydrographic Office

Washington $25, \mathrm{~B}$. C.

The Johns Hopkins University

Department of Physics

Homewood Campus

Baltimore, Maryland

Attn: G. Plass 
Brookhaven National Laboratory

Upton, L. I., New York

Attn: Meteorology Group

Chemical Corps, Biological Iaboratories

Technical Library, Camp Detrick

Frederick, Maryland

Dr. August Raspet

Engineering and Industrial Research Station

Mississippi State College

State College, Mississippi

Dr. E. W. Hewson, Diffusion Project

Round Hill

South Dartmouth, Massachusetts

Dr. Hunter Rouse, Director

Iowa Institute of Hydraulic Research

State University of Iowa

Iowa City, Iowa

Head, Department of Physics

University of New Mexico

Albuquerque, New Mexico

Mr. Wendell A. Mordy

Hawaiian Pineapple Research Institute

Honolulu, Hawaii

Dr. E. G. Bowen, Chief

Division of Radiophysics

Commonwealth Scientific Industrial Research

Organization, University Grounds

Chippendale, N. So Wo, Australia 
Professor Max A. Noodbury

Department of Statistics, Wharton School

University of Pennsylvania

PhiladeIphia 4, Pennsy Ivanic

Pennsyltania State College

School of Mineral Industries

State College, Pennsylvania

Attro: H. Panofsiky

University of Wisconsin

Department of Heteorology

Madison, Wisconsin

Attn: V. Suom

Director of Technical Services

Headquarters, Dugway Proving Grounds

Dugway, Utah

Division of Oceanography

U. S. Navy Hydrographic Office

Washington $25, \mathrm{D}$. C. 